\title{
脳動脈瘤内塞栓術の長期成績
}

\author{
今村博敏 ${ }^{1)}$ 坂井信幸 ${ }^{1)}$ 足立秀光 ${ }^{1)}$ 上野 泰 $^{1)}$ 國枝武治 ${ }^{1)}$ 坂井千秋 ${ }^{2)}$ \\ 小柳正臣 ${ }^{1)}$ 蔵本要二 ${ }^{2)}$ 重松朋芳 ${ }^{1)}$ 五百蔵義彦 ${ }^{1)}$ 今堀太一郎 ${ }^{1)} \quad$ 芝田純也 ${ }^{1)}$ \\ 千原英夫 ${ }^{1)}$ 篠田成英 ${ }^{1)}$ 松田佳子 ${ }^{1)}$ 菊池晴彦 ${ }^{1)}$
}

\section{Long-term Results of Endovascular Embolization of Cerebral Aneurysms}

\author{
Hirotoshi IMAMURA ${ }^{1)}$ Nobuyuki SAKAI ${ }^{1)}$ Hidemitsu ADACHI ${ }^{1)}$ Yasushi UENO ${ }^{1)}$ Takeharu KUNIEDA ${ }^{1)}$ \\ Chiaki SAKAI ${ }^{2)}$ Masaomi KOYANAGI ${ }^{1)}$ Yoji KURAMOTO ${ }^{2)}$ Tomoyoshi SHIGEMATSU ${ }^{1)}$ \\ Yoshihiko IOROI ${ }^{1)}$ Taichiro IMAHORI ${ }^{1)}$ Sumiya SHIBATA ${ }^{1)}$ Hideo CHIHARA $^{1)}$ \\ Narihide SHINODA ${ }^{1)}$ Yoshiko MATSUDA ${ }^{1)}$ Haruhiko KIKUCHI ${ }^{1)}$ \\ 1) Department of Neurosurgery, Kobe City Medical Center General Hospital \\ 2) Division of Neuro Endovascular Therapy, Institute of Biomedical Research and Innovation Hospital
}

\begin{abstract}
O
Objective: The risk of rebleeding and the rate of retreatment are reportedly higher in ruptured cerebral aneurysms treated with endovascular coiling than in those treated with surgical clipping. In this study, we evaluated the frequency and risk factors of recanalization on angiograms after embolization of ruptured and unruptured cerebral aneurysms.

Methods: From April 2001 to December 2003, we performed endovascular embolization on 30 ruptured and 52 unruptured aneurysms. We included 18 ruptured and 40 unruptured aneurysms, which subsequently ruptured, underwent retreatment within 5 years, or were followed up for more than 5 years. We evaluated risk factors of recanalization in terms of location, size, ratio of dome to neck, volume embolization ratio (VER), and remnant flow into aneurysms immediately after embolization.

Results: Nine (50.0\%) ruptured and $11(27.5 \%)$ unruptured aneurysms were recanalized on angiograms. We attempted retreatment for 5 recurrent aneurysms, and were unsuccessful inserting any coils in 3 aneurysms. Recanalization on subsequent angiograms was rare in cases, that were not recanalized on angiograms at 6 months (ruptured aneurysms : $0 \%$ (0/6 cases), versus unruptured aneurysms : $6.7 \%(2 / 30$ cases). VER was the significant risk factor in recanalization of unruptured aneurysms. There were significant differences between VER and recanalization in unruptured aneuryms $(\mathrm{p}=0.027)$, but no significant risk factor related to recanalization in ruptured aneurysms.

Conclusions: Recanalization of unruptured aneurysms was more frequent in cases of low VER than in cases of high VER. It is difficult to predict recurrence and rebleeding of ruptured aneurysms treated with high VER. Long-term results of both ruptured and unruptured aneurysms are considered favorable, if there is no recanalization on angiograms at 6 months.
\end{abstract}

Key Words

cerebral aneurysm, endovascular embolization, recanalization

1）神戸市立医療センター中央市民病院 脳神経外科

(Received April 9, 2010 : Accepted January 7, 2011)

2）先端医療センター病院 脳血管内治療科

<連絡先：今村博敏 ７650-0046 兵庫県神戸市中央区港島中町4-6 E-mail : i-hiro@ $z$ zg7.so-net.ne.jp>

\section{緒 言}

2005年にInternational subarachnoid aneurysm trial (ISAT) ${ }^{5)}$ の結果が報告され，日本でも破裂動脈瘤に対して積極的 に動脈瘤塞栓術が施行されるようになってきている．現 在，当院では動脈瘤塞栓術を第 1 選択に破裂動脈瘤に対 する根治術を施行しているが，開頭術に比べて動脈瘤塞
栓術は再開通の可能性が高い治療方法であり，術後の経 過観察が重要となってくる。今回，我々は瘤内塞栓術を 施行し， 5 年以上の経過観察が可能であった破裂および 未破裂動脈瘤58例に対して，その再開通の危険因子につ いて検討し，報告する． 
Table 1 Location of ruptured and unruptured aneurysms

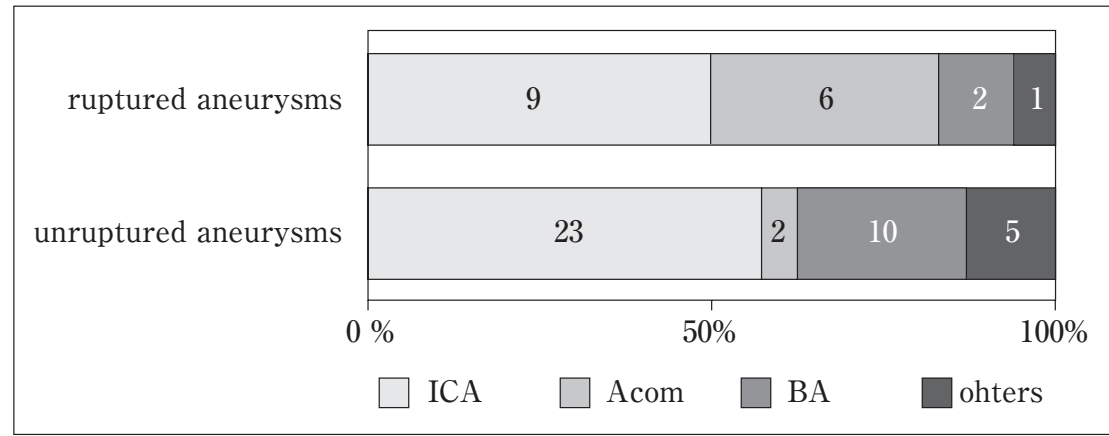

Abbreviations Acom : anterior communicating artery, BA : basilar artery, ICA : internal carotid artery

\section{対象と方法}

2001年 4 月から 2003年12月の期間に脳動脈瘤に対して 瘤内塞栓術を施行した全82例を対象とした。この期間の 脳動脈瘤の治療は，開頭クリッピング術を第一選択とし て施行し，意識レベルや全身状態を考慮した上で血管内 治療がより安全と判断した症例に対して血管内塞栓術を 施行した。内訳は破裂脳動脈瘤が30例，未破裂脳動脈瘤 が52例であり，破裂もしくは再治療を施行した症例，お よび 5 年以上の経過観察が可能であった 58 例に対して経 過観察中の再開通，破裂の有無と，動脈瘤の部位，大き さ, neck長, dome/neck比, 塞栓率, 直後の塞栓状態と の関係について検討した，塞栓術後の脳血管撮影は，破 裂動脈瘤に対しては30日以内および 6 力月後，未破裂動 脈瘤に対しては 6 力月後に施行し，その後は頭部単純写 真やMRAで再開通が疑われた際に脳血管撮影を追加し た. 前回の脳血管撮影の所見と比較して, 動脈瘤内への 造影剂の流入が増加していることを再開通と定義した。

\section{結 果}

脳動脈瘤の部位別の分布をTable 1に示す。破裂脳動 脈瘤は，内頚動脈瘤が 9 例 $(50.0 \%)$, 前交通動脈瘤が 6 例 $(33.3 \%)$ であり，未破裂脳動脈瘤では内頝動脈瘤 が23例 $(57.5 \%)$ ，脳底動脈瘤が10例（25.0\%）を占めた。 経過観察期間は, 破裂脳動脈瘤で平均 68.1 力 $(1.4-101.5$ 力月), 未破裂脳動脈瘤で平均84.7力月（7.3-111.8力月） であった。

\section{1. 破裂脳動脈瘤}

治療から 30 日以内の亜急性期の脳血管撮影を 18 例中 17
例に施行し，再開通を認めた症例は 5 例 $(29.4 \%)$ であ つた。このうち， 1 例の前交通動脈瘤に対して約 2 力月 後に開頭クリッピング術を施行し， 1 例の前交通動脈瘤 は再治療を拒否し，56力月後にくも膜下出血をきたし死 亡した。 また残りの 3 例のうち 1 例の内頝動脈瘤で，そ の後も再開通が進行するため再治療を施行した（Fig. 1).

亜急性期の脳血管撮影で再発を認めなかった 12 例のう ち10例で，約 6 力月後に脳血管撮影を施行した. 10例中 4 例に再開通を認め (Fig. 2)，3 例で血管内治療によ る再治療を試みたが, 2 例はコイルを追加できなかった. 再治療を断念した 2 例は，右脳底動脈一上小脳動脈分岐 部の小さな動脈瘤と，右内頝動脈後交通動脈分岐部の大 型動脈瘤でアクセスが困難であった。再治療を断念した 2 例と, 再治療を施行しなかった 1 例では, 経過観察中 にさらなる再開通や破裂は認めなかった。

6 力月後の脳血管撮影でも再発を認めなかった 6 例は その後の脳血管撮影，もしくはMRAで再開通は認めな かった (Fig. 3).

再開通を認めた 9 例と，認めなかった 9 例に関して， その部位，大きさ，neck長， dome/neck比，塞栓率，直 後の塞栓状態について統計学的解析を行ったが，すべて 再開通との関係について有意差は認めなかった (Table 2).

\section{2. 未破裂脳動脈瘤}

未破裂脳動脈瘤40例のうち，38例で約 6 力月後に脳血 管撮影を施行したが， 8 例 $(21.1 \%)$ で再開通を認めた. 脳底動脈の小さな脳動脈瘤に対して血管内治療による再 治療を試みたが, コイルを追加することはできなかった. また，これら 8 症例のうち 1 例の脳底動脈瘤で，その後 も再開通の進行を認め, 抗血小板薬の休薬に伴い脳梗塞 

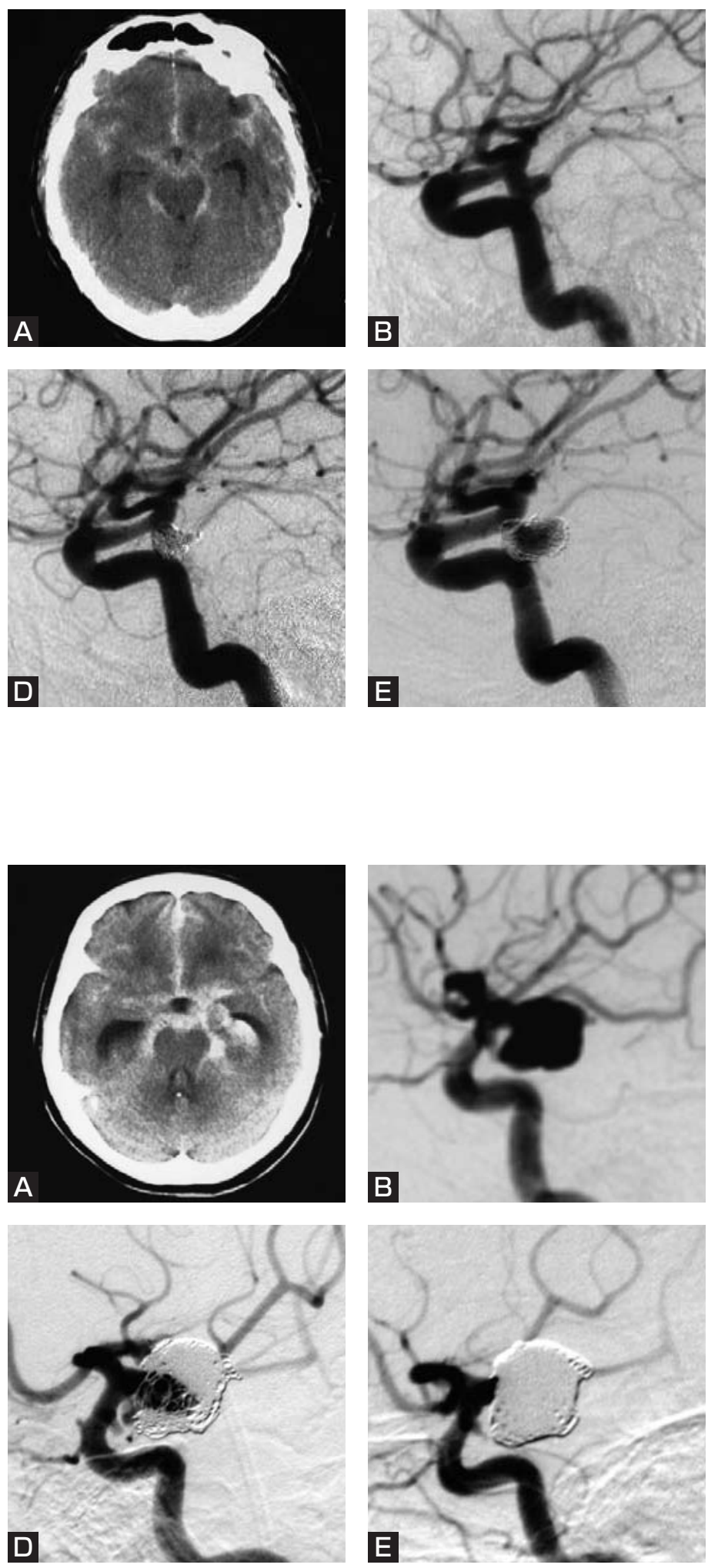

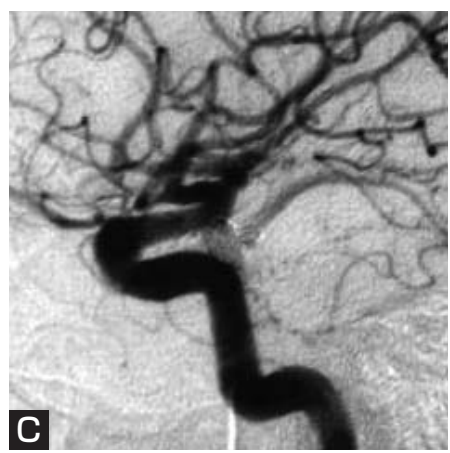

Fig. 1 Representative case

A : CT scan of a 51-year-old man on the first admission reveals diffuse subarachnoid hemorrhage.

B : Initial angiogram shows an aneurysm arising from the left internal carotid artery-posterior communicating artery bifurcation.

C : Angiogram immediately after the first embolization demonstrates the complete obliteration of the aneurysm.

D : Orifice of the aneurysm is slightly opened on angiogram 19 days after the first embolization.

E : Angiogram at 6 months after the embolization shows major recanalization of the aneurysm.

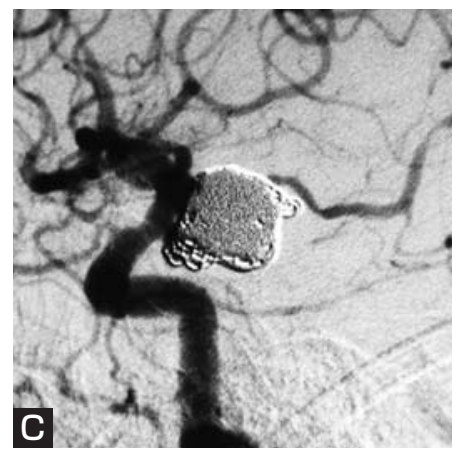

Fig. 2 Representative case

A : CT scan of a 73-year-old woman on the first admission reveals diffuse subarachnoid hemorrhage with intracerebral hematoma in the left temporal lobe and intraventricular hematoma.

B : Initial angiogram shows an aneurysm arising from the left internal carotid artery-posterior communicating artery bifurcation.

C : Angiogram immediately after the first embolization demonstrates the complete obliteration of the aneurysm.

D : Angiogram at 6 months demonstrates major recanalization of the aneurysm.

E : Angiogram immediately after the second embolization performed 7 months after the first treatment. She died of the second subarachnoid hemorrhage at 26 months after the first hemorrhage. 


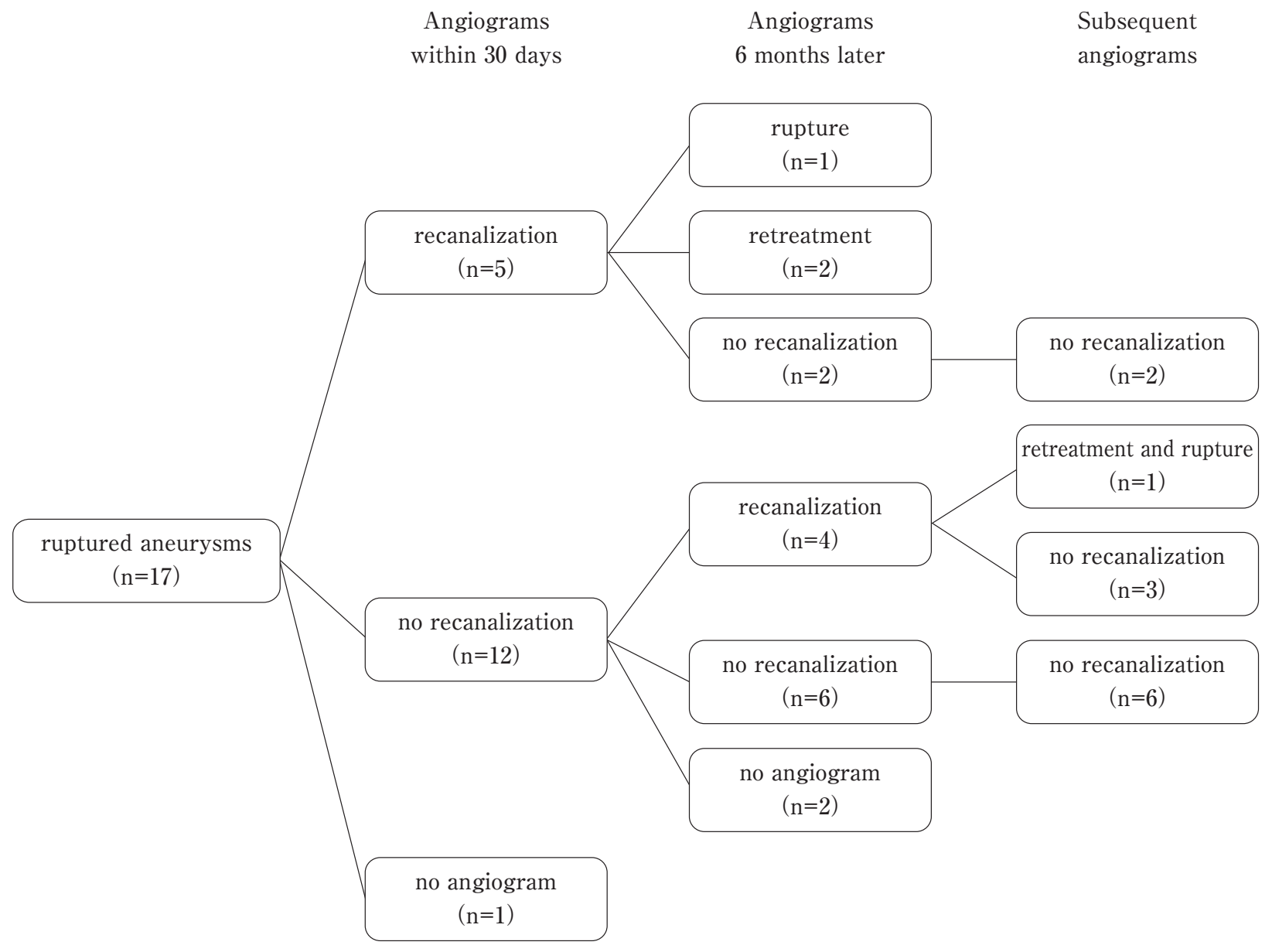

Fig. 3 Results of follow-up angiography on ruptured aneurysms

Table 2 Analysis of recanalization after embolization of ruptured aneurysms

\begin{tabular}{|c|c|c|c|}
\hline & $\begin{array}{l}\text { With recanalization } \\
\qquad(\mathrm{n}=9)\end{array}$ & $\begin{array}{l}\text { Without recanalization } \\
\qquad(\mathrm{n}=9)\end{array}$ & $P$ value \\
\hline Age & 62.2 & 59.3 & 0.595 \\
\hline Sex (male : female) & $6: 3$ & $2: 7$ & 0.058 \\
\hline Location & & & 0.733 \\
\hline ICA & 4 & 5 & \\
\hline Acom & 4 & 2 & \\
\hline $\mathrm{BA}$ & 1 & 1 & \\
\hline others & 0 & 1 & \\
\hline Aneurysm size $(\mathrm{mm})$ & 8.05 & 8.01 & 0.980 \\
\hline Neck size $(\mathrm{mm})$ & 3.67 & 3.28 & 0.484 \\
\hline Aspect ratio (dome/neck) & 2.37 & 2.42 & 0.891 \\
\hline Remodeling technique (no: balloon) ${ }^{\dagger}$ & $8: 8$ & $1: 1$ & 1.000 \\
\hline VER $(\%)$ & 27.12 & 29.86 & 0.522 \\
\hline $\mathrm{CO}: \mathrm{NR}: \mathrm{BF}$ & $4: 4: 1$ & $4: 5: 0$ & 0.574 \\
\hline
\end{tabular}

Abbreviations Acom : anterior communicating artery, BA : basilar artery, BF : body filling,

$\mathrm{CO}:$ complete occlusion, ICA : internal carotid artery, NR : neck remnant,

VER : volume embolization ratio

$\dagger$ : number of patients and that of the balloons used for remodeling technique 


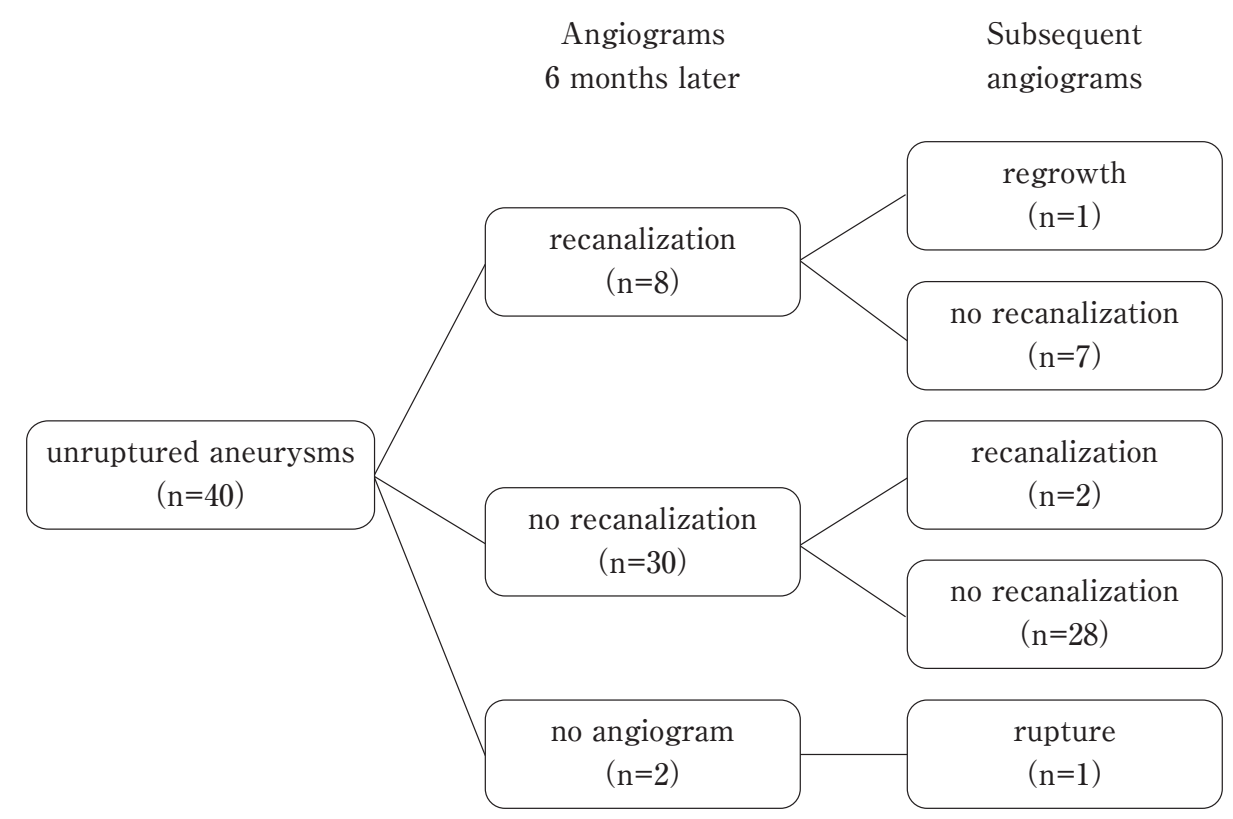

Fig. 4 Results of angiographic follow-up on unruptured aneurysms

Table 3 Analysis of recanalization after embolization of unruptured aneurysms

\begin{tabular}{|c|c|c|c|}
\hline & $\begin{array}{l}\text { With recanalization } \\
\qquad(\mathrm{n}=11)\end{array}$ & $\begin{array}{l}\text { Without recanalization } \\
\qquad(\mathrm{n}=29)\end{array}$ & $P$ value \\
\hline Age & 58.9 & 57.5 & 0.785 \\
\hline Sex (male : female) & $1: 10$ & $7: 22$ & 0.288 \\
\hline Location & & & 0.794 \\
\hline ICA & 7 & 16 & \\
\hline Acom & 0 & 2 & \\
\hline $\mathrm{BA}$ & 3 & 7 & \\
\hline others & 1 & 4 & \\
\hline Aneurysm size (mm) & 9.74 & 6.90 & 0.140 \\
\hline Neck size $(\mathrm{mm})$ & 4.83 & 3.75 & 0.273 \\
\hline Aspect ratio (dome/neck) & 2.06 & 1.93 & 0.633 \\
\hline Remodeling technique (no: balloon : stent) ${ }^{\dagger}$ & $7: 4: 0$ & $17: 9: 3$ & 0.538 \\
\hline VER (\%) & 19.07 & 26.10 & $0.027^{*}$ \\
\hline $\mathrm{CO}: \mathrm{NR}: \mathrm{BF}$ & $4: 6: 1$ & $15: 11: 3$ & 0.629 \\
\hline
\end{tabular}

Abbreviations Acom : anterior communicating artery, BA : basilar artery, BF : body filling, CO : complete occlusion, ICA : internal carotid artery, NR : neck remnant, VER : volume embolization ratio

* significantly different on univariate analysis $(p<0.05)$

$\dagger$ : number of patients and that of the balloons and stents used for remodeling technique

を合併した．

6 力月後の脳血管撮影で再開通を認めなかった 30 例の

うち，2 例で治療からそれぞれ $23 ， 56$ 月後の脳血管撮 影で再開通を認めた．残りの 29 例は，経過観察中の脳血 管撮影やMRA上，再開通は認めなかった (Fig. 4).

再開通を認めた11例と，認めなかった29例に関して， その部位，大きさ，neck長， dome/neck比，塞栓率，直 後の塞栓状態について統計学的解析を行ったが，塞栓率 が低いものは有意に再開通が多い結果であった $(\mathrm{p}=0.027) \quad$ (Table 3$).$ 


\section{考 察}

2001年 4 月から 2003 年12月までに当科で治療したす心゙ ての動脈瘤の脳血管撮影上の再開通率は $34.5 \%$ であ た。この中で再治療を実際に施行した症例は破裂動脈瘤 4 例，未破裂動脈瘤 1 例の 5 例（8.6\%）であり，これ までの報告と同様の再治療率であった 子に関して統計学的解析を行ったが，未破裂動瘤におい て塞栓率が低い症例で再開通が有意に多く認められた一 方で，破裂動脈瘤では再開通の予測因子は特定できなか った.

Holmin らの報告では 1 年後の脳血管撮影上の再開通 の有無が長期成績に強く相関していたが3)，自験例でも 6 力月後の脳血管撮影で再開通を認めなかった 36 例のう ち，その後の長期経過で再開通を認めた症例は，破裂動 脈瘤で 2 例であった。一方， 6 力月後の脳血管撮影で再 開通を認めたが再治療を施行しなかった15例中，再開通 の進行を認めた症例は 2 例であった。以上の結果から， 動脈瘤塞栓術後の脳血管撮影は 6 力月後に施行すること は妥当であると考える. Holminらの報告と比較すると， 自験例の進行性の再開通の頻度は低かったが，これは破 裂動脈瘤の割合が少ないことが原因かもしれない.

未破裂動脈瘤の塞栓術後再開通の危険因子はこれまで に報告されておらず，自験例では塞栓率が低い症例で有 意に再開通が多い結果であった。一方で破裂動脈瘤にお いて再開通に対して有意に影響を与える危険因子は特定 することができなかった．これまでにも年齢，大きさ， 塞栓後の残存，再発動脈瘤などが塞栓術後の再開通の危 険因子として報告されているが1,7-9)，統一した結論はな い. 我々の結果は，破裂動脈瘤の母集団が少ないことが 原因かもしれないが，破裂動脈瘤の血行動態は未破裂動 脈瘤とは異なることが報告されて打り ${ }^{2)}$ ，高い塞栓率で の瘤内塞栓術が行えても再開通をきたす動脈瘤が破裂動 脈瘤に多く含まれている可能性がある.

破裂動脈瘤と未破裂動脈瘤を比較すると，これまでの 報告にもあるように破裂動脈瘤の塞栓術後の再開通率 は，未破裂動脈瘤に比べて高い結果であった ${ }^{7)}$ 。このた め，破裂動脈瘤と未破裂動脈瘤の再発に関しては，別々 に評価していく必要があると考えている．また，破裂動 脈瘤の塞栓術後の再破裂がこれまでにも報告されてお $り^{1,4-6,8)}$, ISATの結果でも外科的手術群と比較して再出 血が有意に多く認められていること年，その致死率が 非常に高いことからも ${ }^{8)}$, 破裂動脈瘤の塞栓術後の経過
観察はより慎重に行う必要ある。我々の施設でも，破裂 動脈瘤の塞栓術後に再開通を認めていた症例で追加治療 を拒否された前交通動脈瘤は，約4年後にくも膜下出血 を再び発症した．また破裂内頝動脈瘤で，再塞栓術の19 カ月後にくも膜下出血によると思われる突然死をきたし ている，一方で，未破裂動脈瘤では経過観察中にくも膜 下出血を合併した症例は認めなかった，破裂動脈瘤の再 開通は，塞栓術後30日以内の早期から進行する症例があ り，6 カ月後の脳血管撮影までの期間に頭部単純写真や MRAで急速な再開通の進行の有無を確認しなければな らない。

\section{結 論}

未破裂動脈瘤の再開通は塞栓率が低い症例に多く認め られた。しかし，破裂動脈瘤は未破裂動脈瘤と比較して 再開通率が高いにもかかわらず，その予測が困難であっ た．再開通を認めた症例は再出血する可能性があり，早 期より頭部単純写真や，MRAで再開通の有無を確認し, 再開通が進行する症例では再治療が必要である．塞栓術 6 力月後の脳血管撮影で再開通を認めない症例の長期成 績は，良好であった。

\section{文 献}

1) Campi A, Ramzi N, Molyneux AJ, et al: Retreatment of ruptured cerebral aneurysms in patients randomized by coiling or clipping in the International Subarachnoid Aneurysm Trial (ISAT). Stroke 38:1538-1544, 2007.

2 ) Cebral JR, Mut F, Weir J, et al: Quantitative Characterization of the Hemodynamic Environment in Ruptured and Unruptured Brain Aneurysms. AJNR (in press).

3 ) Holmin S, Krings T, Ozanne A, et al: Intradural saccular aneurysms treated by Guglielmi detachable bare coils at a single institution between 1993 and 2005: clinical longterm follow-up for a total of 1810 patient-years in relation to morphological treatment results. Stroke 39:2288-2297, 2008.

4 ) Kremer C, Groden C, Lammers G, et al: Outcome after endovascular therapy of ruptured intracranial aneurysms: morbidity and impact of rebleeding. Neuroradiology 44:942-945, 2002.

5 ) Molyneux AJ, Kerr RS, Yu LM, et al: International subarachnoid aneurysm trial (ISAT) of neurosurgical clipping versus endovascular coiling in 2143 patients with ruptured intracranial aneurysms: a randomised comparison of effects on survival, dependency, seizures, rebleeding, subgroups, and aneurysm occlusion. Lancet 366:809-817, 2005. 
6 ) Molyneux AJ, Kerr RS, Birks J, et al: Risk of recurrent subarachnoid haemorrhage, death, or dependence and standardised mortality ratios after clipping or coiling of an intracranial aneurysm in the International Subarachnoid Aneurysm Trial (ISAT): long-term follow-up. Lancet Neurol 8:414-415, 2009.

7 ) Piotin M, Spelle L, Mounayer C, et al: Intracranial aneurysms: treatment with bare platinum coils-aneurysm packing, complex coils, and angiographic recurrence.
Radiology 243:500-508, 2007.

8 ) Sluzewski M, van Rooij WJ: Early rebleeding afater coiling of ruptured cerebral aneurysms: incidence, morbidity, and risk factors. AJNR 26:1739-1743, 2005.

9 ) Yu SC, Chan MS, Boet R, et al: Intracranial aneurysms treated with Guglielmi detachable coils: midterm clinical and radiological outcome in 97 consecutive Chinese patients in Hong Kong. AJNR 25:307-313, 2004.

\section{要 旨}

【目的】破裂打よび未破裂動脈瘤に対する瘤内塞栓術後の再開通の危険因子について検討した.【対象】2001年 4 月から2003年12 月に瘤内塞栓術を施行した 82 例の動脈瘤のうち，5 年以上の経過観察が可能であった破裂動脈瘤18例，未破裂動脈瘤40例を対 象とした。【結果】破裂動脈瘤，未破裂動脈瘤の再開通は，それぞれ 9 例 $(50.0 \%) ， 11$ 例（27.5\%）に認められた。その中で 5 例 に再治療を試みたが， 3 例ではコイルを留置できなかった. 塞栓術 6 カ月後の脳血管撮影で再開通を認めずに，その後の経過 観察中に再開通を認めた症例は，破裂動脈瘤，未破裂動脈瘤でそれぞれ 0 例， 2 例（6.7\%）とまれであった。未破裂動脈瘤， 破裂動脈瘤の再開通の危険因子は未破裂動脈瘤では低い塞栓率であったが, 破裂動脈瘤の再開通予測因子を特定できなかった.【結 論】破裂動脈瘤は塞栓率が高くても再開通することがあるが，破裂，未破裂動脈瘤ともに6 月月後の脳血管撮影で再開通を認め なければ，その後の長期成績は良好であった。 